\title{
Use of morphometry and immunohistochemistry of small intestinal biopsy specimens in the diagnosis of food allergy
}

\author{
PCM ROSEKRANS ${ }^{1}$, CJLM MEIJER ${ }^{2}$, CJ CORNELISSE ${ }^{2}$, AM vd WAL ${ }^{2}$, \\ AND J LINDEMAN ${ }^{2}$ \\ From the ${ }^{1}$ Department of Gastroenterology and ${ }^{2}$ Department of Pathology, University Medical Center, \\ Leiden, The Netherlands
}

SUMMARY Eight babies with cow's milk protein intolerance and malabsorption, ages ranging from 2 weeks to 6 months, and five adult patients with a history of food allergy were studied. In the jejunal biopsies of the eight children with cow's milk protein intolerance we found partial villous atrophy with an increased number of interepithelial lymphocytes as determined by morphometric analysis. In the five adult patients no morphological changes of the jejunal mucosa were found. However, immunoperoxidase staining revealed a markedly increased number of IgE containing cells in the lamina propria of all jejunal biopsies studied. This proved to be specific for young and adult patients with food allergy. It is concluded that immunohistochemistry of jejunal biopsy specimens is of considerable value in the diagnosis of food allergy.

Allergic reactions, of both the immediate and delayed
type, to a variety of ingested antigens have been
reported by various authors. . $^{1-4}$ Although intoler-
ance to certain foodstuffs is clinically obvious, it is
important to distinguish between non-immunological
causes, for example, a deficiency of brush-border
enzymes such as lactase, and allergic reactions.
Moreover, it is a diagnostic problem to distinguish
food allergy from functional gastrointestinal dis-
orders. Therefore histological confirmation of the
diagnosis of food allergy is important. Immunological tests are not always helpful. ${ }^{5,6}$ Skin tests with extracts of allergen occasionally show immediate type (type I) reactions to food. ${ }^{7}$ However, negative results occur, often due to the instability of allergen extracts. Another problem is that the preparation of the allergen abstract is possible only from whole foodstuffs and not from products of digestion which actually cause the allergic reaction in the patient. False-positive skin tests frequently occur in atopic individuals due to non-specific histamine liberators.

It has been shown that the radioallergosorbant test (RAST) for specific IgE dietary antibodies is not reliable in the diagnosis of food allergy. For example, high titres of circulating antibodies to $\beta$ lacto-

Received for publication 18 June 1979 globulin or egg proteins may be found not only in some patients with food allergy but also in patients with gluten-sensitive enteropathy. In the latter patients, this finding is probably not specific for food allergy but is secondary to injury of the small intestinal mucosa..$^{8-10}$

A challenge test with a suspected food allergen is easy to interpret if the reaction appears promptly after the food has been ingested, but in some cases the reaction is delayed and in others the challenge test is negative. ${ }^{7,11}$

We present our study on the jejunal biopsies from eight children with cow's milk protein intolerance and from five adult patients with food allergy against foodstuffs of various origins in order to find objective morphological and immunohistochemical parameters to confirm the clinical diagnosis of food allergy.

\section{Patients}

Jejunal biopsies from two groups of patients with food allergy were studied. One group consisted of eight patients, 2 weeks to 6 months of age, with cow's milk protein intolerance. Six of the eight children came from Mediterranean countries. Five had a family history of asthma. All the children suffered from diarrhoea and vomiting shortly after 
introduction of cow's milk to their diet; some patients failed to thrive. Jejunal biopsies were taken, either while the patients were still taking cow's milk or within one week of starting a cow's milk free diet. All children became free of symptoms after elimination of the cow's milk from the diet. Those children who failed to thrive showed a rapid gain of weight. Bacterial or protozoal disease was excluded. A provocation test with cow's milk was performed in all eight patients and caused an immediate recurrence of diarrhoea and vomiting in six. In two patients diarrhoea or vomiting recurred on the third and sixth days respectively after reintroduction of cow's milk. Three patients were biopsied one month after elimination of cow's milk and again two days after cow's milk provocation.

The second group consisted of five women with a history of diarrhoea. Three patients had asthma or allergic rhinitis. All five patients reported intolerance to certain kinds of food, manifested by diarrhoea, vomiting, headache, urticaria, and bronchospasm soon after ingesting the food. The allergens varied (egg, chicken, seafood, chocolate, nuts), and it was not always possible to induce symptoms by exposure to the suspected allergen. Avoidance of the allergen was successful in three patients. The other two ( 9 and 10, Table 1) became free of symptoms after treatment with disodium cromoglycate (Lomudal ${ }^{\mathrm{R}}$ ).

The jejunal biopsies of 10 healthy volunteers and of 30 patients with a variety of gastrointestinal diseases, such as gluten-sensitive enteropathy, Crohn's disease, irritable colon syndrome, and lactase deficiency, served as controls.

\section{Methods}

Peroral biopsies of the small intestinal mucosa were performed under radiological control using a hydraulic multiple biopsy capsule. Two biopsy specimens were taken distal to the ligament of Treitz. One was oriented under a dissecting microscope with a minimum of handling on a 'mesh' to which it adhered. ${ }^{12}$ The second specimen was fixed without handling in a sublimate-formaldehyde mixture. ${ }^{13}$ After fixation for 3 hours the tissue samples were embedded in paraplast. Tissue sections were cut $4 \mu \mathrm{m}$ thick, perpendicular to the luminal surface and mounted on glass slides. Sections were stained with haematoxylin and eosin (HE) and periodic acid Schiff (PAS), and specifically for IgA, IgM, IgG, IgD, and IgE heavy chains using indirect immunoperoxidase staining. ${ }^{13}$ Appropriate controls were done according to Sternberger. ${ }^{14}$ Rabbit antisera against IgA, IgM, and IgG heavy chains were purchased from Dakopatts (Denmark). The rabbit antisera against IgD and IgE heavy chains were purchased from the Central Laboratory of the Netherlands Red Cross Blood Transfusion Service, Amsterdam. The specificity of the antisera was confirmed by immunoelectrophoresis and for IgA, IgG, IgM, and IgD by cytoplasmic immunofluorescence on monoclonal bone marrow preparations. ${ }^{15}$ The rabbit anti IgE antiserum showed no cytoplasmic immunofluorescence with bone marrow preparations monoclonal for IgA, IgM, IgG, or IgD heavy chains and their respective $\kappa$ or $\lambda$ light chains. Horseradish peroxidase-labelled goat anti rabbit IgG was obtained from Miles-Yedah (Israel).

Table 1 Clinical data and jejunal biopsy findings of 13 patients with food allergy

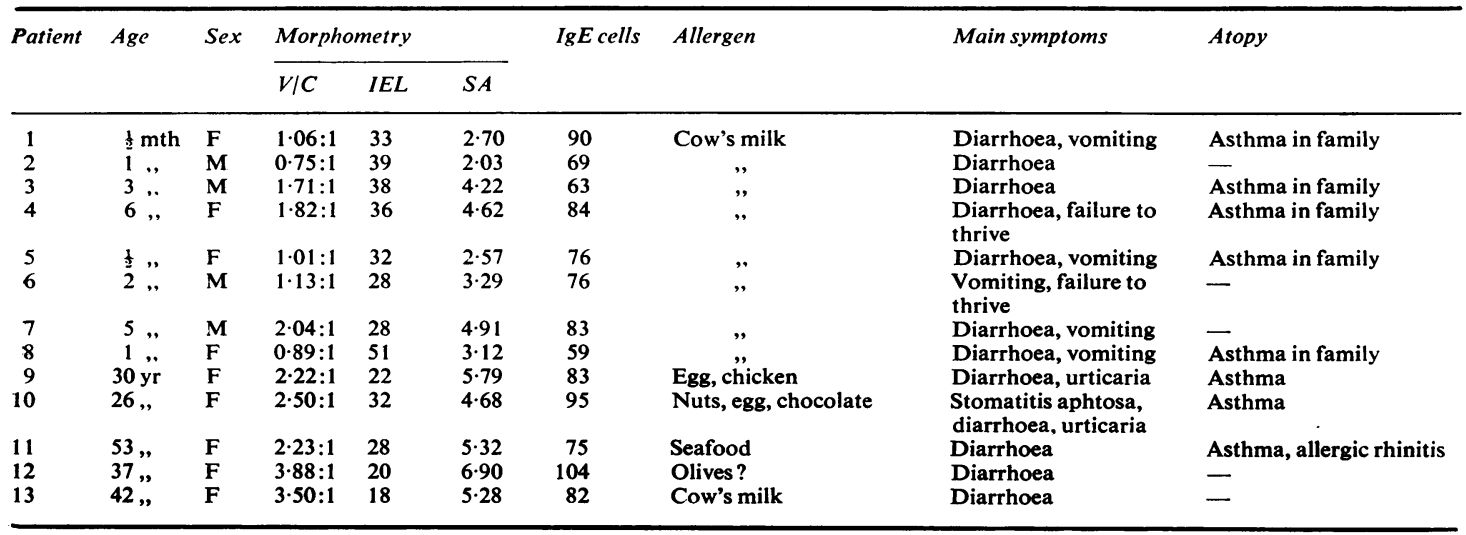

$\mathrm{V} / \mathrm{C}=$ villous :crypt ratio; $\mathbf{I E L}=$ number of interepithelial lymphocytes per mm surface epithelium; $\mathrm{SA}=$ length of surface epithelium in $\mathrm{mm}$ per $\mathrm{mm}$ muscularis mucosae; IgE cells = number of IgE containing cells per mm² lamina propria area. 


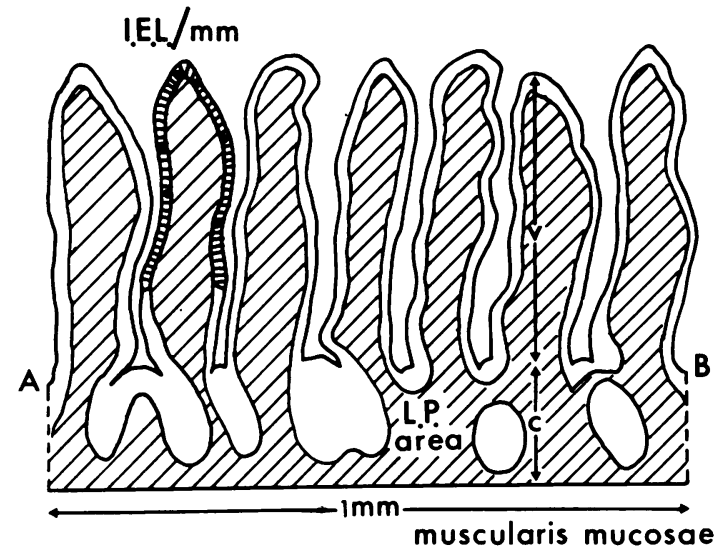

Fig. 1 Morphometry of jejunal biopsies: $v / c=$ villous: crypt ratio; $I E L=$ number of interepithelial lymphocytes per mm surface epithelium; $A B=$ length of surface epithelium per $\mathrm{mm}$ stretched muscularis mucosae; $L P$ area = lamina propria cross-sectional area per $\mathrm{mm}$ stretched muscularis mucosae.

The HE slides were used for morphometric studies. The following parameters were measured (Fig. 1):

(a) mean villous to crypt ratio, that is, the linear measurement of five villous heights divided by the corresponding crypt depths (v/c);

(b) number of interepithelial lymphocytes per millimetre surface epithelium counted in the upper two-thirds of the villus (IEL);

(c) length of surface epithelium per millimetre stretched muscularis mucosae (SA);

(d) lamina propria cross-sectional area per millimetre stretched muscularis mucosae (LP area).

Images of the HE and immunoperoxidase stained sections were projected with a standard magnification of $\times \mathbf{2 0 0}$ on graph paper, and drawings were made. Morphometric analysis of the drawn contours was made on a graphic tablet (Tektronix) interfaced to a small laboratory computer (PDP 11/10: Digital Equipment Corporation, Maynard, Mass.). ${ }^{16}$

The slides stained for IgA, IgM, IgG, IgD, and IgE were used for counting the immunoglobulincontaining cells per $\mathrm{mm}^{2}$ lamina propria area in three consecutive sections.

Statistical analysis was performed using the Student $t$ test.

\section{Results}

The initial proximal jejunal biopsy, performed as soon as possible after cow's milk protein allergy in the group of young children was suspected, showed in all cases partial villous atrophy. The villous:

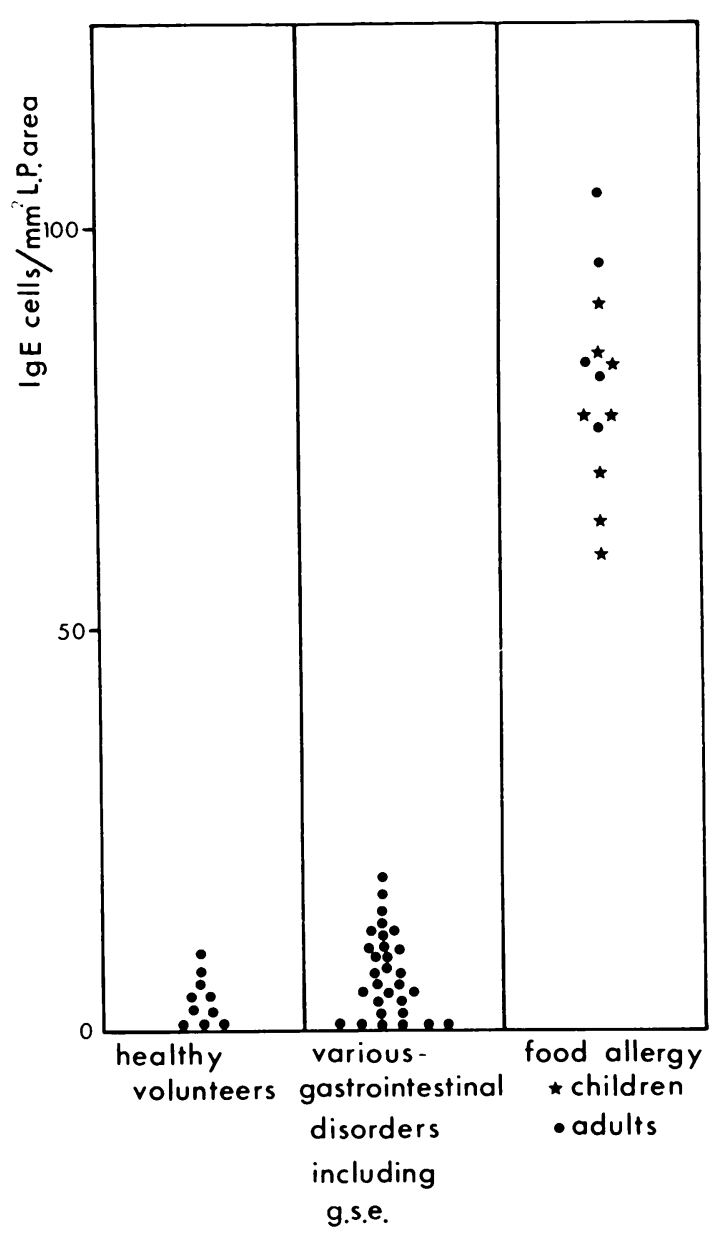

Fig. 2 Number of IgE containing cells per $\mathrm{mm}^{2}$ lamina propria area. Statistical analysis showed no significant difference between the group of healthy volunteers and patients with various gastrointestinal disorders including gluten-sensitive enteropathy $(\mathrm{P}=0 \cdot 1)$. However, the patients with food allergy showed a significant difference against both groups $(\mathrm{P}<0.0005)$.

crypt ratio was reduced, but total villous atrophy was never found (Table 1). The number of interepithelial lymphocytes was increased but the number per millimetre surface mucosa was not as high as we found in gluten-sensitive enteropathy (data not shown). The cellular density of the lamina propria was slightly increased and consisted of plasma cells, eosinophils, granulocytes, and mononuclear cells. In most cases there was a relative increase of eosinophils. The number of IgE-containing cells in the lamina propria was markedly increased (Fig. 2). The 
absolute and relative number of $\operatorname{IgA}$ and $\operatorname{IgM}$ containing cells was slightly increased in most patients intolerant to cow's milk protein.

In the adult group, we found no morphological changes of the small intestinal mucosa. The villous: crypt ratio was normal, and the number of interepithelial lymphocytes and the cellular density in the lamina propria were indistinguishable from normal. The immunoperoxidase staining, however, showed a striking increase in the number of IgE containing cells similar to the findings in the group with cow's milk protein intolerance (Fig. 3). In the adult group, the absolute and relative number of $\mathrm{IgA}, \mathrm{IgG}$, and IgM containing cells did not differ substantially from that of the controls.

In three patients with cow's milk protein intolerance, biopsies were taken one month after elimination of cow's milk and two days after reintroduction of cow's milk in the diet. After elimination of cow's milk, the villous:crypt ratio and the length of surface epithelium outline per millimetre muscularis mucosae improved markedly and became almost normal (normal v/c $>2 \cdot 0$ ). The number of interepithelial

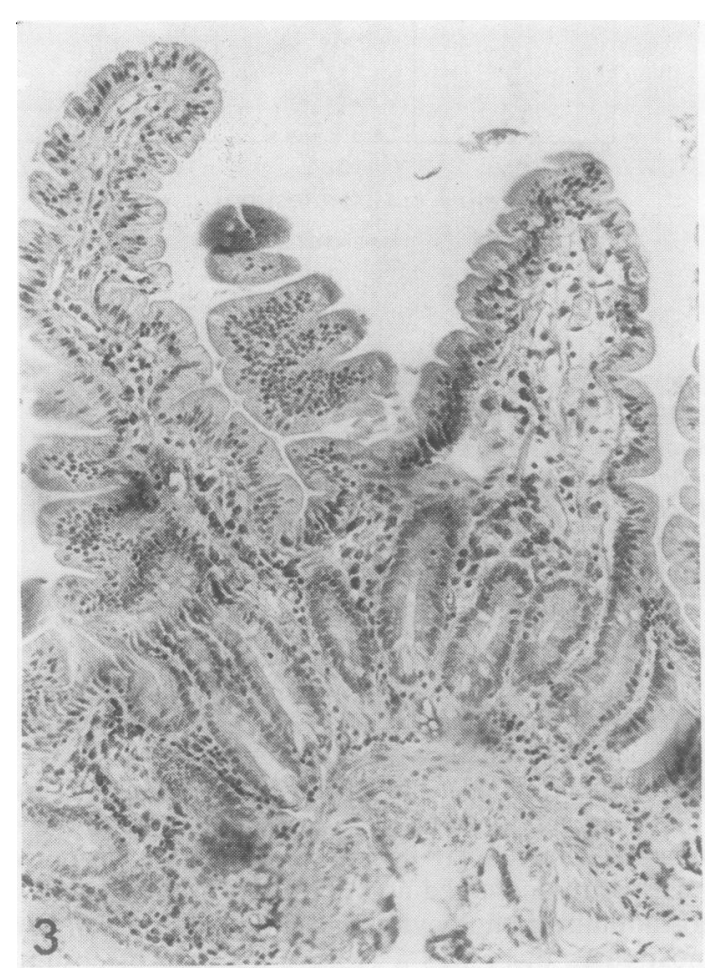

Fig. 3 Jejunal biopsy stained for IgE of an adult patient (11) with food allergy. lymphocytes decreased but remained above normal. The number of IgE containing cells did not change (Table 2). After cow's milk challenge the results of the morphometric studies were indistinguishable from those before cow's milk elimination (Fig. 4).

Table 2 Morphometric results of serial jejunal biopsies of three patients with cow's milk protein intolerance

\begin{tabular}{|c|c|c|c|c|}
\hline & $v / c \pm S D$ & $I E L$ & $S A$ & JgE cells \\
\hline $\begin{array}{l}\text { Patient } 1 \\
\text { On cow's milk } \\
1 \text { month after elimination } \\
3 \text { days after provocation }\end{array}$ & $\begin{array}{l}1.06( \pm 0 \cdot 16) \\
1 \cdot 67( \pm 0 \cdot 15) \\
1 \cdot 38( \pm 0.07)\end{array}$ & $\begin{array}{l}33 \\
25 \\
28\end{array}$ & $\begin{array}{l}2 \cdot 70 \\
4 \cdot 83 \\
3 \cdot 48\end{array}$ & $\begin{array}{l}90 \\
72 \\
83\end{array}$ \\
\hline $\begin{array}{l}\text { Patient } 2 \text { (Fig. } 4 \text { ) } \\
\text { On cow's milk } \\
1 \text { month after elimination } \\
2 \text { days after provocation }\end{array}$ & $\begin{array}{l}0.75( \pm 0 \cdot 12) \\
2 \cdot 17( \pm 0 \cdot 31) \\
0.96( \pm 0 \cdot 18)\end{array}$ & $\begin{array}{l}39 \\
20 \\
31\end{array}$ & $\begin{array}{l}2 \cdot 03 \\
6 \cdot 09 \\
2 \cdot 63\end{array}$ & $\begin{array}{l}69 \\
82 \\
89\end{array}$ \\
\hline $\begin{array}{l}\text { Patient } 6 \\
\text { On cow's milk } \\
1 \text { month after elimination } \\
2 \text { days after provocation }\end{array}$ & $\begin{array}{l}1.13( \pm 0.12) \\
1.52( \pm 0.11) \\
1.37( \pm 0.17)\end{array}$ & $\begin{array}{l}28 \\
22 \\
24\end{array}$ & $\begin{array}{l}3 \cdot 29 \\
3 \cdot 88 \\
3 \cdot 84\end{array}$ & $\begin{array}{l}76 \\
76 \\
65\end{array}$ \\
\hline
\end{tabular}

$\mathrm{v} / \mathrm{c}=$ mean villous $:$ crypt ratio: IEL $:=$ number of interepithelial lymphocytes per $\mathrm{mm}$ surface epithelium; $\mathbf{S A}=$ length of surface epithelium in $\mathrm{mm}$ muscularis mucosae; IgE cells = number of IgE containing cells per $\mathrm{mm}^{2}$ lamina propria area.

\section{Discussion}

In both the juvenile and the adult group of patients with clinical symptoms of food allergy we found a marked increase in the number of IgE containing cells in the proximal jejunal lamina propria. Partial villous atrophy with an increased number of intraepithelial lymphocytes occurred in the group of young children with cow's milk protein intolerance only. We did not find increased numbers of IgE containing cells in the jejunal lamina propria in any of the healthy volunteers. In the group of patients with a variety of gastrointestinal abnormalities, only those with gluten-sensitive enteropathy showed a slight increase in the number of IgE containing cells in jejunal biopsies. This might be caused by the same mechanism that leads to the formation of circulating antibodies to food allergens in gluten-sensitive patients.

The distribution of immunoglobulin-containing cells in the intestinal lamina propria of infants suffering from the cow's milk induced malabsorption syndrome was studied by Jos et al. ${ }^{17}$ They found an increased number of IgA containing cells using an immunofluorescence technique. Savilahti ${ }^{11}$ studied the cell counts during cow's milk challenge and observed a rise in IgA, IgM, and IgG containing cells but found no consistent change in the number of IgE containing cells. In similar challenge investigations, however, Shiner et al. ${ }^{18}$ showed an increase in 

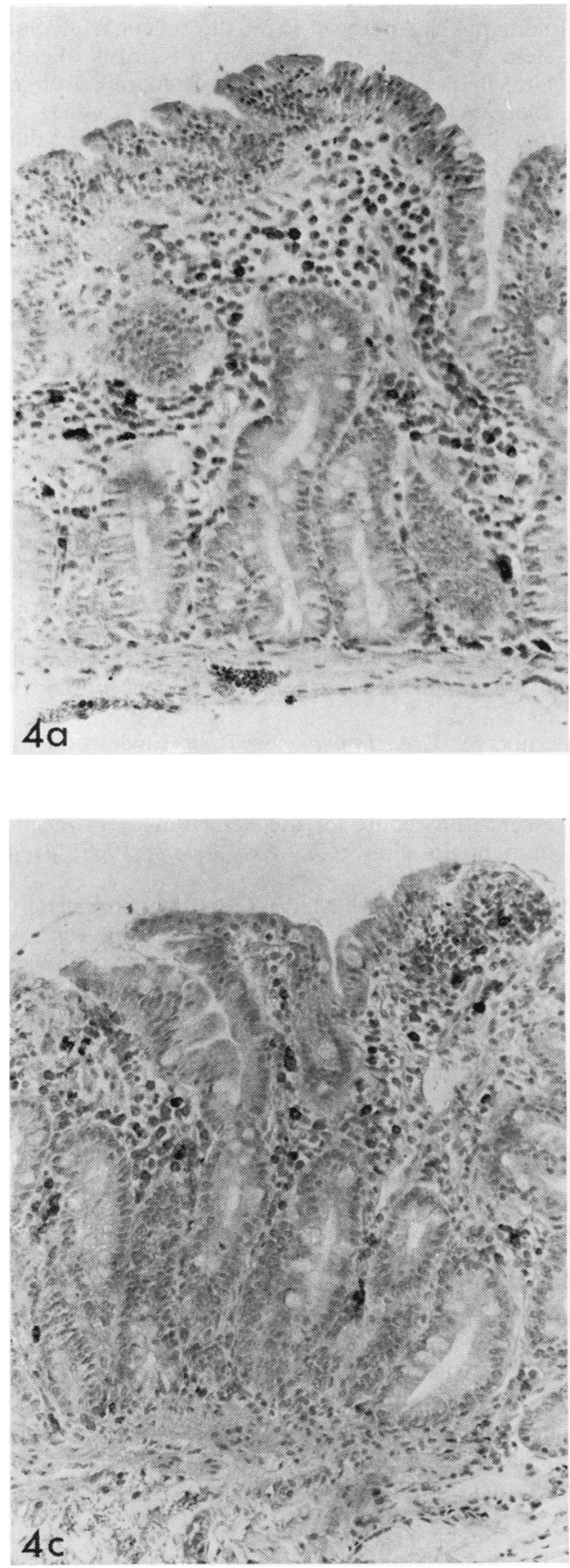

Fig. 4 Three jejunal biopsies stained for IgE from patient 2 with cow's milk protein intolerance: (a) taken during cow's milk containing diet; (b) taken one month after elimination of cow's milk from the diet; (c) taken two days after cow's milk provocation.

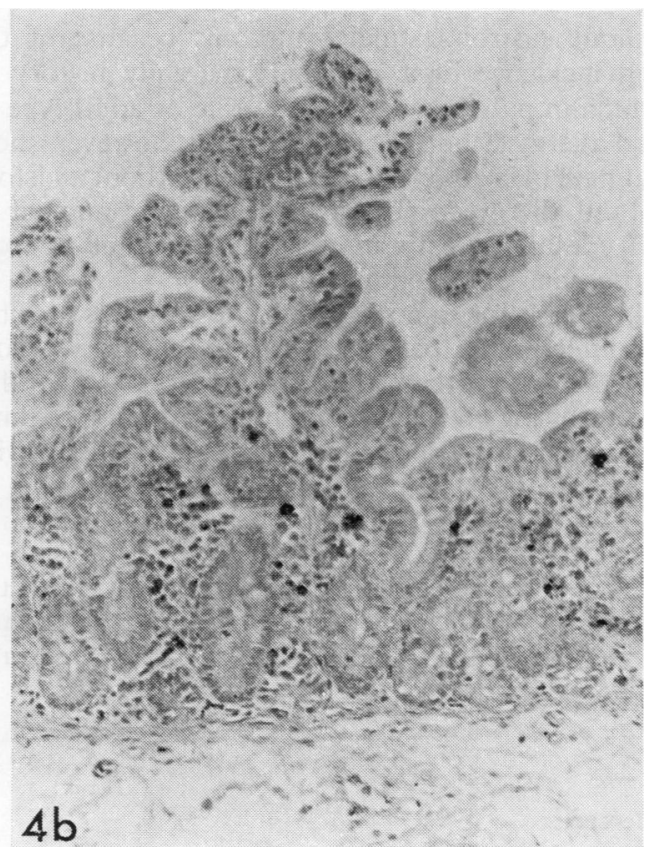

mucosal IgE containing cells. It is not easy to compare these results. In most immunohistochemical studies of IgE, workers have neglected to test the anti IgE reagent on positive and negative substrates. Standardised studies based on properly defined and characterised reagent are necessary. ${ }^{19}$

During the past decades food allergy has gained increased recognition as an important factor in intestinal disorders. The best defined type of food allergy is the allergy to cow's milk. Yet, in spite of many carefully performed clinical studies on the symptomatology of milk allergy, even today the diagnostic criteria are difficult to define. The final diagnosis is based mainly on the results of clinical provocation tests after a favourable response to elimination of cow's milk. ${ }^{7}$ Sumithran and Iyngkaran ${ }^{20}$ claimed that there is no clinical justification for jejunal biopsy in infants in whom cow's milk protein intolerance is suspected. In our opinion, the clinical evidence derived from cow's milk challenge after an elimination diet is unreliable. It is important to find objective criteria on which the diagnosis of food allergy can be based, and to distinguish it from other diseases of the small intestine. A single jejunal biopsy, performed when the diagnosis of food allergy is suspected, is, in our opinion, sufficient to confirm the diagnosis.

It seems worth-while to examine small intestinal mucosa biopsies from atopic patients with clinical allergic manifestations of bronchial asthma and 
without gastrointestinal symptoms because of the high incidence of a personal or family history of asthma in patients with the juvenile or adult type of food allergy. Studies now in progress, however, show that patients with bronchial asthma without a history of food allergy do not have an increased number of IgE containing cells in the jejunal lamina propria (Rosekrans, in preparation).

In conclusion, our study indicates that it is possible to differentiate patients with food allergy from patients with other kinds of gastrointestinal disorders using immunohistochemistry of proximal jejunal biopsy specimens in combination with morphometry.

The cooperation of the paediatric department of the University Medical Center Leiden and the Juliana Kinderziekenhuis, Den Haag, is gratefully acknowledged.

\section{References}

${ }^{1}$ Kuitunen P, Visakorpi J K, Hallman N. Histopathology of duodenal mucosa in malabsorption syndrome induced by cow's milk. Annales Paediatrici 1965; 205: 54-63.

${ }^{2}$ Truelove S C, Wright R. In: Gell P G H, Coombs R $\mathrm{R}$ A, eds. The Intestine in Allergic Diseases in Clinical Aspects of Immunology. Oxford: Blackwell. 1968; 1053-1062.

${ }^{3}$ Bleumink E. Food allergy, the chemical nature of the substances eliciting symptoms. World Rev Nutr Diet 1970; 12: 505-570.

${ }^{4}$ Freier S. Paediatric gastrointestinal allergy. In: Brostoff $\mathrm{J}$, ed. Clinical Immunology-Allergy in Paediatric Medicine. Oxford: Blackwell. 1974; 107128.

${ }^{5}$ Dannaeus A, Johansson S G O, Foucard T, Öhman S. Clinical and immunological aspects of food allergy in childhood. I. Estimation of IgG, IgA, and IgE antibodies to food antigens in children with food allergy and atopic dermatitis. Acta Paediatr Scand 1977; 66: 31-37.

${ }^{6}$ Dannaeus A, Johansson S G O, Foucard T. Clinical and immunological aspects of food allergy in childhood. II. Development of allergic symptoms and humoral immune response to foods in infants of atopic mothers during the first 24 months of life. Acta Paediatr Scand 1978; 67: 497-504.
${ }^{7}$ Goldman A S, Anderson D W, Jr, Sellers W A, Saperstein S, Kniker W T, Halpern S R. Milk allergy. I. Oral challenge with milk and isolated milk proteins in allergic children. Pediatrics 1963; 32: 425-443.

${ }^{8}$ Carswell F, Ferguson A. Plasma food antibodies during withdrawal and reintroduction of dietary gluten in coeliac disease. Arch Dis Child 1973; 48: 583-586.

${ }^{9}$ Bleumink E. Allergens and toxic proteins in food. In: Hekkens W Th J M, Peña A S, eds. Coeliac Disease. Leyden: Stenfert Kroese. 1974; 46-55.

${ }^{10}$ Eastham E J, Walker W A. Adverse effects of milk formula ingestion on the gastrointestinal tract. Gastroenterology 1979; 76: 365-374.

${ }^{11}$ Savilahti E. Immunochemical study of the malabsorption syndrome with cow's milk intolerance. Gut 1973; 14: 491-501.

${ }^{12}$ Rubin C E, Brandborg L L, Phelps P C, Taylor H C, Jr. Studies of celiac disease. I. The apparent identical and specific nature of the duodenal and proximal jejunal lesion in celiac disease and idiopathic sprue. Gastroenterology 1960; 38: 28-49.

${ }^{13}$ Bosman F T, Lindeman J, Kuiper G, van der Wal A Kreunig $J$. The influence of fixation on immunoperoxidase staining of plasmacells in paraffin sections of intestinal biopsy specimens. Histochemistry 1977; 53: 57-62.

${ }^{14}$ Sternberger L A. Immunochemistry. Englewood Cliffs, NJ: Prentice Hall Inc. 1974: 53.

${ }^{15}$ Hijmans W, Schuit H R E, Klein F. An immunofluorescence procedure for the detection of intracellular immunoglobulins. Clin Exp Immun 1969; 4: 457472.

${ }^{16}$ Van de Velde C J H, Meijer C J L M, Cornelisse C J, van de Velde $E$ A, van Putten $L$ M, Zwaveling A. A morphometrical analysis of lymph node responses to tumors of different immunogenicity. Cancer Res 1978; 38: 661-667.

${ }^{17}$ Jos J, Rey J, Frézal J. Etude immunohistochimique de la muqueuse intestinale chez l'enfant I. Les syndromes de malabsorption. Arch Fr Pediatr 1972; 29: 681-698.

${ }^{18}$ Shiner M, Ballard J, Smith M E. The small-intestinal mucosa in cow's milk allergy. Lancet 1975; 1: 136140.

${ }^{19}$ Brandtzaeg $\mathrm{P}$, Baklien $\mathrm{K}$. Inconclusive immunohistochemistry of human IgE in mucosal pathology (Letter). Laicet 1976; 1: 1297-1298.

${ }^{20}$ Sumithran $\mathbf{E}$, Iyngkaran N. Is jejunal biopsy really necessary in cow's milk protein intolerance? Lancet 1977; 2 : 1122-1123.

Requests for reprints to: Dr PCM Rosekrans, Depart- N ment of Gastroenterology, University Medical Center Rijnsburgerweg 10, Leiden, The Netherlands 